\title{
Long term follow-up demonstrating stability and patient satisfaction of minimally invasive punch technique for percutaneous bone anchored hearing devices
}

Yaeesh Sardiwalla', Nicholas Jufas ${ }^{2,3,4}$ and David P. Morris ${ }^{1,2,5^{*}}$ (i)

\begin{abstract}
Objective: Minimally Invasive Ponto Surgery (MIPS) was recently described to facilitate the placement of percutaneous bone anchored hearing devices. As early adopters of this new procedure, we sought to perform a quality assurance project using our own small prospective cohort to justify this change in practice. We chose to examine device stability and to gauge our patients' perspective of the surgery and their overall satisfaction with the process.
\end{abstract}

Methods: A total of 12 adult patients who underwent MIPS between 2016 and 2017 with a minimum postoperative follow-up of 12 months were included in this study. A prospective MIPS research clinic was used to follow patients, assess the implant site soft tissue status and gather qualitative information through patient interviews and surveys.

Results: The mean (SD) soft tissue status score averages using the IPS Scale were low for inflammation 0.1 (0.1), pain 0.1 (0.1), skin height $0.2(0.1)$ and total IPS score 0.4 (0.3) indicating minimal soft tissue changes. Patient experiences with MIPS were overwhelmingly positive in reports through the MIPS modified SSQ-8. All patients reported speedy recoveries and no long-term complications. There were zero device losses.

Conclusion: The series presented in this paper represents the first MIPS cohort with long term follow-up to be published to date in North America. Our findings conclude both device stability and patient satisfaction with no loss of fixtures. Consequently, we have adopted MIPS as our procedure of choice for the placement of all percutaneous BAHDs.

Keywords: Patient safety, Otologic surgical procedures, Bone conduction, Minimally invasive surgical procedures, Patient satisfaction, Quality improvement

\section{Introduction}

In 2011, Hultcrantz et al. described the Minimally Invasive Ponto Surgery (MIPS) procedure where a $5 \mathrm{~mm}$ dermal punch was used to remove the limited tract of soft tissue needed to accommodate the Ponto (Oticon, Copenhagen, Denmark) abutment [1]. The drilling procedure could

\footnotetext{
* Correspondence: dp.morris@dal.ca

${ }^{1}$ Faculty of Medicine, Dalhousie University, Halifax, NS, Canada

${ }^{2}$ Division of Otolaryngology - Head and Neck Surgery, Dalhousie University, Halifax, NS, Canada

Full list of author information is available at the end of the article
}

then be completed in seconds through a cannula placed to protect the skin and soft tissues while holding cooling fluid. MIPS heralded a departure from the traditional "open approach" to percutaneous fixture placement. Soft tissue preservation and longer abutments placed in a few simple surgical steps marked a significant evolution of the original surgical procedure. While keen to adopt this simplified approach, we were equally vigilant to discover whether such changes were possible without compromise to patient care.

(c) The Author(s). 2018 Open Access This article is distributed under the terms of the Creative Commons Attribution 4.0 International License (http://creativecommons.org/licenses/by/4.0/), which permits unrestricted use, distribution, and 
In our groups previously published direct cost analysis, we calculated that MIPS offered a saving of approximately $\$ 450$ per operation when compared to open approaches [2]. The majority of this saving stems from the large time saving with MIPS procedure $(0.10 \mathrm{~h})$ versus the open approach $(1.13 \mathrm{~h})$ [2]. We were also able to move bone anchored hearing device (BAHD) surgery out of the main operating room (OR) with this transition, making valuable OR time accessible for other services [2].

In this follow-up study, we sought to investigate the long-term stability of the fixture/abutment in our single-center Halifax cohort. Early evidence from soft tissue preserving techniques for BAHD have already suggested favorable outcomes [3, 4]. To date, there have been few MIPS case series published. Bonilla et al. showed promising MIPS outcomes in their cohort, confirming a shorter procedure time and fewer skin complications one week after surgery when compared to the linear incision technique [5]. While details of other experiences are limited, there are mixed results reported [6]. The highly anticipated long-term, multi-centre MIPS outcomes data recently published showed no difference in inflammation compared to linear incisions [7-9]. There was improvement in skin sensation, sagging, cosmetic result and reduction of surgical time but a non-significant increase in implant extrusion rate that warrants further investigation [7-9].

Generally, it is accepted that osseointegration and implant stability occurs within 3 months for adults and 6 months for children [10-12]. This period has traditionally been used to guide the timing for loading the abutment. We reasoned that if the fixtures were to fail or have complications, they would do so early after surgery. We proposed a minimum follow-up period of 12 months to capture such failures.

As early adopters of this new procedure, we sought to perform a quality assurance project using our own small prospective cohort to justify this change in practice. As medical professionals, we balance the introduction of new techniques and intervention with patient safety, especially where large bodies of evidence do not yet exist [10]. We chose to examine device stability and to gauge our patients' perspective of the surgery and their overall satisfaction with the process.

\section{Methods}

\section{Patient selection and surgery}

Institutional permission from Nova Scotia Health Authority Research Ethics Board was obtained to conduct the quality assurance of the new MIPS technique. A total of 12 sequential adult patients who underwent MIPS between 2016 and 2017 with a minimum post-operative follow-up of 12 months were prospectively enrolled in this study at the time of proceeding with surgery. All cases were performed or directly assisted and supervised by the same experienced consultant otologist. Specific training covering the MIPS procedure and novel drilling technique in both an animal and synthetic temporal bone model had been undertaken prior to the first real-time surgery. Exclusive MIPS cases were performed under local anesthetic. General anesthesia was reserved for those undergoing concomitant middle ear or mastoid surgery. Cases requiring general anesthesia were performed in the main OR. Most local anesthesia cases were performed in a minor procedures room conforming to Infection Prevention and Control standards. For an overview of the surgical technique and equipment required for MIPS, please review our groups previous article on this topic [2]. Sound processors were loaded at median of 6 weeks, with a range from 4 to 6 weeks. Table 1 shows complete demographic information.

The details of each surgical case, fixture/abutment specifications, external BAHD chosen and operating time was recorded. Each patient's surgical data is captured in Table 2. The MIPS operating time was calculated prospectively from the moment of skin punch, to the moment the healing cap was placed.

\section{Research clinic}

Follow-up was prospective. A coordinated MIPS research clinic was used to follow patients, assess implant sites and gather qualitative information through patient interviews and surveys. Soft tissue status around the implant was evaluated independently by three different assessors (staff otologist, otology fellow and senior medical student) using the eight point Inflammation, Pain, Skin Height (IPS) Scale proposed by Kruyt [13]. The IPS scale was designed to assess long-term wound healing at the bone conduction site using objective and patient reported measures of inflammation (skin integrity, erythema, edema and granulation tissue), pain and skin height/numbness to prompt treatment decisions. This addresses the shortcomings of the Holgers scale such as dichotomous subjective responses, not considering long-term wound healing failures such as increased skin height and not encapsulating patient pain [13-15]. Patients qualitative perspectives were assessed using the Surgical Satisfaction Questionnaire (SSQ-8) modified for MIPS and through a semi-structured interview that assessed their experience. The modified SSQ-8 asked patients to use a Likert Scale (1 - very satisfied; 5 - very unsatisfied) to rate their MIPS surgical experience according 8 domains: the result of their surgery, their recovery, satisfaction with abutment length, appearance of 
Table 1 The demographic information and operative characteristics from the cohort of MIPS patients followed for a minimum of 12 months

\begin{tabular}{|c|c|c|c|c|c|c|c|}
\hline Age & Sen & Previous Diagnosis & Follow-up Duration & Surgery & Admission & Anesthesia & Site \\
\hline 74 & $\mathrm{~F}$ & Psoriasis and Left Mastoid cavity & 30 months & MIPS & Day Case & Local & Main OR \\
\hline 58 & M & $\begin{array}{l}\text { Chronic Suppurative Otitis Media - } \\
\text { Previous mastoidectomy }\end{array}$ & 30 months & MIPS & Day Case & General & Main OR \\
\hline 57 & $\mathrm{~F}$ & Chronic Suppurative Otitis Media & 28 months & MIPS + Mastoid obliteration & Admitted & General & Main OR \\
\hline 58 & M & Chronic Suppurative Otitis Media & 24 months & MIPS & Day Case & Local & Main OR \\
\hline 28 & $\mathrm{~F}$ & Chronic Suppurative Otitis Media & 23 months & MIPS + Mastoid obliteration & Day Case & General & Main OR \\
\hline 55 & M & Chronic Suppurative Otitis Media & 20 months & MIPS + Mastoid obliteration & Admitted & General & Main OR \\
\hline 55 & M & Chronic Suppurative Otitis Media & 18 months & MIPS and Left Tympanoplasty & Admitted & General & Main OR \\
\hline 52 & $\mathrm{~F}$ & Chronic Suppurative Otitis Media & 14 months & MIPS + Blind Sac closure & Admitted & General & Main OR \\
\hline 30 & M & $\begin{array}{l}\text { Chronic Suppurative Otitis Media } \\
\text { Tympanomastoidecomy }\end{array}$ & 20 months & MIPS & Day Case & Local & Minor Procedures \\
\hline 65 & $\mathrm{~F}$ & CSOM preexisting mastoid cavity & 20 months & MIPS & Day Case & Local & Minor Procedures \\
\hline 41 & M & Right Microtia & 19 months & MIPS & Day Case & Local & Minor Procedures \\
\hline 74 & M & CSOM & 17 months & MIPS & Day Case & Local & Minor Procedures \\
\hline
\end{tabular}

screw, the follow-up they received, overall satisfaction and how likely they would be to recommend MIPS to others who require BAHD. Both the IPS scale and modified SSQ-8 were administered at the patient's most recent follow-up visit.

\section{Statistical analysis}

Data from all three observers' IPS scores were analyzed independently and were averaged. Only descriptive analysis was used since this is a small sample evaluation.
Box and whisker plots of survey data were used to present responses.

\section{Results}

The mean (SD) soft tissue status score averages using the IPS Scale were low for inflammation 0.1 (0.1), pain $0.1(0.1)$, skin height $0.2(0.1)$ and total IPS score 0.4 (0.3) indicating minimal soft tissue changes. There was good inter-rater reliability with these scores. Table 3 shows the summarized IPS results. Digital photographs

Table 2 Technical information relating to the MIPS surgery for each of the 12 patients. For each procedure 50 N.cm of torque was obtained. * Topical application of ciprofloxacin/dexamethasone drops (Ciprodex ${ }^{\oplus}$ ) around abutment

\begin{tabular}{|c|c|c|c|c|c|c|}
\hline $\begin{array}{l}\text { Sound } \\
\text { Processor }\end{array}$ & $\begin{array}{l}\text { Abutment (and change } \\
\text { if applicable) }\end{array}$ & Implant & $\begin{array}{l}\text { Length of } \\
\text { Surgery (mins) }\end{array}$ & $\begin{array}{l}\text { Skin thickness } \\
(\mathrm{mm})\end{array}$ & $\begin{array}{l}\text { Number of } \\
\text { turns }\end{array}$ & Adjunctive Measures \\
\hline $\begin{array}{l}\text { Left Ponto Plus } \\
\text { power }\end{array}$ & 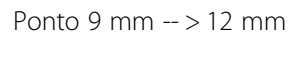 & 4 mm Ponto BHX & 8.2 & 4.5 & $\mathrm{~S}$ & Abutment lengthened \\
\hline Left BAHA S & Ponto $12 \mathrm{~mm}$ & 4 mm Ponto BHX & 9.5 & 7 & 4.5 & Ciprodex* drops 'local toilet"* \\
\hline Left BAHA 5 & Ponto $12 \mathrm{~mm}$ & 4 mm Ponto BHX & 4 & 6 & $\mathrm{~S}$ & Stay suture applied interiorly \\
\hline $\begin{array}{l}\text { Right Ponto Plus } \\
\text { power }\end{array}$ & Ponto $9 \mathrm{~mm}$ & $4 \mathrm{~mm}$ Wide Ponto & 9.6 & 5 & 4.5 & None \\
\hline Left BAHA S & Ponto $12 \mathrm{~mm} \mathrm{-->9} \mathrm{mm}$ & $4 \mathrm{~mm}$ Wide Ponto & 8 & S & 4.5 & $\begin{array}{l}\text { Abutment shortened Ciprodex* } \\
\text { 'local toilet'* }\end{array}$ \\
\hline Right BAHA S & Ponto $12 \mathrm{~mm}$ & $4 \mathrm{~mm}$ Wide Ponto & S.2 & 6 & 3.25 & None \\
\hline Right BAHA S & Ponto 12 mm & 4 mm Ponto BHX & 6 & $\mathrm{~S}$ & 4.5 & $\begin{array}{l}\text { Direct trauma to implant, close } \\
\text { examination - no apparent harm }\end{array}$ \\
\hline Left BAHA S & Ponto 12 mm & 4 mm Ponto BHX & 4.2 & 6 & 5 & $\begin{array}{l}\text { Slight skin redundancy superiorly } \\
\text { at implant site }\end{array}$ \\
\hline Right Baha 5 & Ponto $12 \mathrm{~mm}$ & 4 mm Ponto BHX & 7 & 7 & 4.5 & None \\
\hline $\begin{array}{l}\text { Right Ponto } \\
\text { Plus }\end{array}$ & Ponto 12 mm & 4 mm Ponto BHX & 8 & 6 & 4.25 & None \\
\hline Right Baha 5 & Ponto $12 \mathrm{~mm}$ - > $9 \mathrm{~mm}$ & 4 mm Ponto BHX & 7 & $\mathrm{~S}$ & 4.5 & Abutment shortened \\
\hline $\begin{array}{l}\text { Right Ponto } \\
\text { Plus }\end{array}$ & Ponto $9 \mathrm{~mm}$ & 4 mm Ponto BHX & 4.5 & 4 & 4.5 & None \\
\hline
\end{tabular}


Table 3 A summary of the IPS-scale soft tissue status for patients at their most recent follow-up where they were seen by 3 independent raters

\begin{tabular}{llllllllllllll}
\hline & \multicolumn{1}{l}{ Inflammation } & \multicolumn{1}{l}{ Pain } & \multicolumn{4}{c}{ Skin Height } & \multicolumn{3}{c}{ Total Score } \\
\hline Rater & 1 & 2 & 3 & 1 & 2 & 3 & 1 & 2 & 3 & 1 & 2 & 3 \\
Score & 0.3 & 0.1 & 0.0 & 0.2 & 0.0 & 0.0 & 0.3 & 0.1 & 0,2 & 0.8 & 0.2 & 0.2 \\
Average & 01 & & & 0.1 & & & 0.2 & & & 0.4 & & \\
\hline
\end{tabular}

corroborated these findings. Figure 1 shows a sample of such images.

There were few minor complications as can be seen by the soft tissue score. The most common intervention in the early post-operative period was the prescription of topical antimicrobial drops on an 'as required' basis should the patient experience redness or irritation. Later complications noted included 3 patients with abutment length changes, the requirement of stay sutures inferiorly and skin redundancy superiorly. Most importantly, there were no failures to osseointegrate and no fixtures had been lost in this cohort at the time of last follow-up.

In terms of survey data, median $(\mathrm{M})$ and Interquartile Range (IQR) from the MIPS modified SSQ-8 were: result of surgery $1(1)$, recovery $1(1,2)$, abutment length satisfaction $1.5(1,2)$, appearance of screw $2(1,2)$, follow-up received $1(1,2)$, overall satisfaction $1(1,2)$, and recommendation of MIPS to others who would benefit 1 (1). Figure 2 presents a graphic summary of modified SSQ-8 survey data.

The patient experiences with MIPS were overwhelmingly positive. All patients reported speedy recoveries, often getting back to routine activities the next day. The surgical experience was felt to be minimized, with patient's reporting they received high quality care. Issues reported included getting used to having a foreign object on their head and initial maintenance of the implant site. Some patients reported wearing their devices with a degree of selectivity, only using them in more challenging listening environments. A segment from a semi-structured patient interview is included below:

\section{"I had a screw failure with my previous bone conduction surgery. It was a much better experience with MIPS when I was awake. There was virtually no recovery afterwards - I went shopping 1 hour later. This was compared to my previous surgery with lots of bleeding, bandages and overnight admission. I wear my device all the time."}

\section{Discussion}

As clinicians, we sense a responsibility to carefully assess and evaluate new developments in patient treatment to ensure that the best quality of care continues to be delivered. The MIPS technique is different from the traditional open approach with which most surgeons are familiar, in a number of ways. Visual access to the bony skull is limited to the narrow tract maintained by the cannula.

A steady hand to stabilize the cannula position and fine tactile feedback are needed to confirm that each pass of the drill is aligned with the original $3 \mathrm{~mm}$ test hole. Confirmation that the fixture/abutment assembly has also engaged the countersunk hole once the cannula is removed also demands tactile recognition. The assistance of an experienced second pair of hands cannot be over emphasized. Unlike the
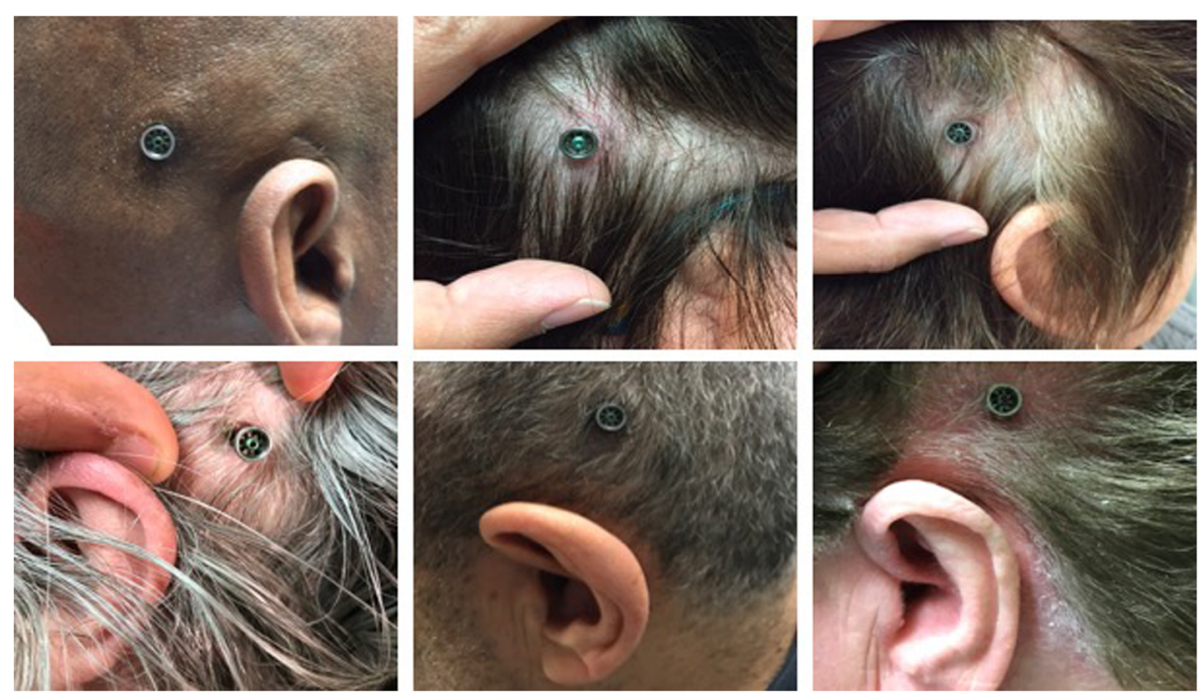

Fig. 1 A sample of follow-up abutment site pictures taken at the parallel research clinic most recent visit 


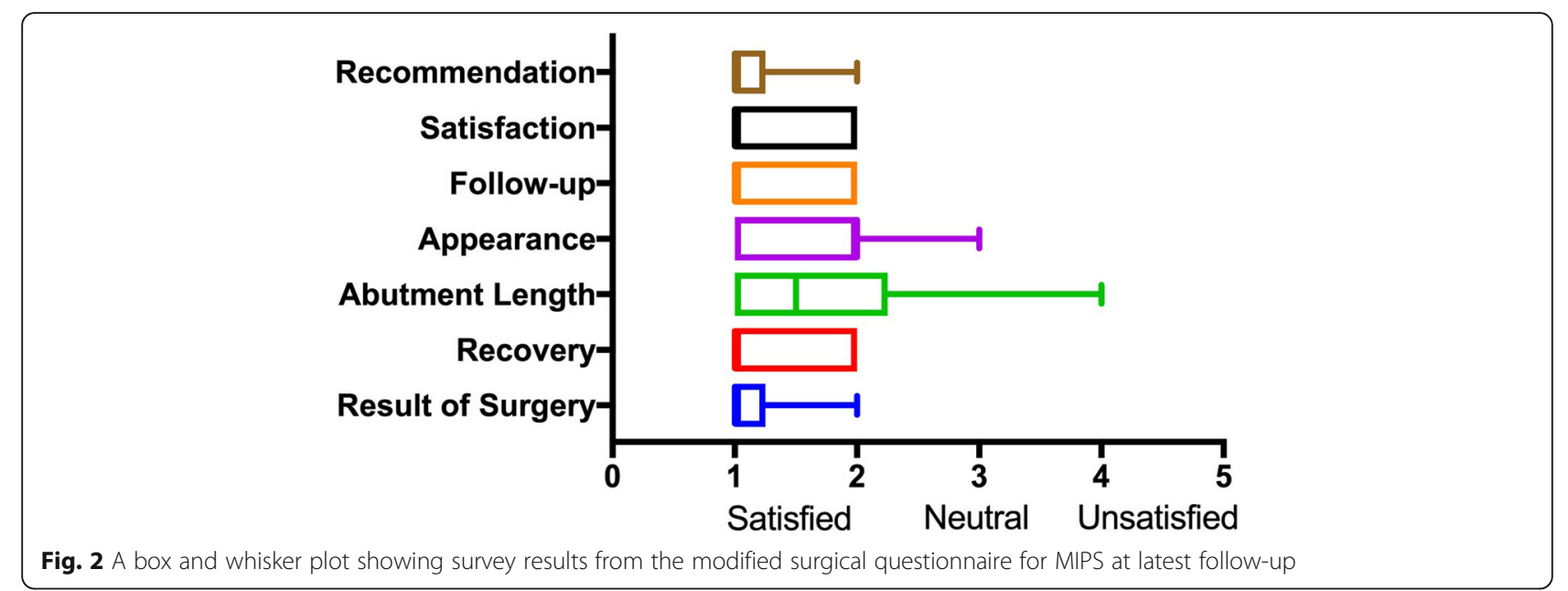

traditional open approach, it is impossible to do this procedure alone. The operating surgeon must maintain the cannula in a stable position for the short duration of the case. The assistant is responsible for the swift loading of drill bits, the application of saline irrigation to the operative site and ultimately attaching the fixture/abutment assembly to the handpiece.

The drills are also very different from what went before. It is intuitive that prolonged drilling, failure to irrigate sufficiently with saline and malalignment of drilling trajectory could all result in fixture failure. As the cannula can only hold a small volume of saline irrigant, this should be cold and not from the warming cabinet. Drilling time should also be as short as possible to prevent heating. Constant refilling of the cannula between stages and removal of bone dust also seems intuitive. At the very end of the procedure, excessive leverage should be avoided when uncoupling the connection to handpiece instrument from the secured abutment. This maneuver risks disturbing even the most perfect of placements and is particularly risky given the increased length of abutments needed when soft tissues are not reduced.

While keen to adopt this simplified approach, we were equally keen to discover whether such changes were possible without compromise to patient care. After performing a round dozen cases, a self-imposed moratorium was observed until sufficient reassurance had been obtained to justify an ongoing change in practice.

Our study has demonstrated that it is possible to maintain secure fixture/abutment placement with the MIPS procedure. With a minimum follow-up of 1 year, skin complications were low, consistent with other invetigators [4]. Implants were stable, and it is reassuring to us that no fixtures were lost in this highly-scrutinized cohort. We have previously shown that this change in practice comes with benefits of cost efficiency and better resource allocation [2].
Here we show additional value in proven patient satisfaction with the MIPS procedure in addition to the well documented improvements in quality of life for BAHD users $[16,17]$.

It is likely that both training and case selection will have some bearing on surgical outcome. Repeated practice of the surgical steps in a training model prior to real-time surgery would seem to be a prudent prerequisite to successful fixture placement even for those who consider themselves to be experienced surgeons with the traditional system. It is humbling to acknowledge the natural learning curve of any new procedure no matter how simple it may seem. The consequences of failure are significant to the patient.

As the MIPS procedure is performed without soft tissue reduction, longer abutments are used with the same $4 \mathrm{~mm}$ fixture of purchase on the skull. Simple rotational physics dictates that increasing the distance from the fulcrum reduces the load necessary to exert a displacing force. This principle is explained by Archimedes' Law of the Lever:

Torque $(\mathrm{N} . \mathrm{m})=$ Force $(\mathrm{N}) \mathrm{x}$ distance $(\mathrm{m})$ from fulcrum

The thicker the scalp, the longer is the required abutment. We note that all our cohort received an abutment of $12 \mathrm{~mm}$ or $9 \mathrm{~mm}$. No cases required the longer $14 \mathrm{~mm}$ abutment which still relies on just $4 \mathrm{~mm}$ of skull purchase. As other centers report their results, it will be interesting to see whether the $14 \mathrm{~mm}$ abutments are as stable as we have found the $9 \mathrm{~mm}$ and $12 \mathrm{~mm}$ abutments to be. If this is not the case, some discretion in patient selection may be appropriate.

A limitation of this study relates to the modified SSQ-8 use for MIPS. Although the SSQ-8 has been independently validated for urogynecological surgeries, the adapted form used for this study has not been 
studied in the context of otologic surgeries. The survey data was congruent with the interview results, with both methods suggesting encouraging experiences with MIPS. This at least provided the reassurances we were seeking from a quality assurance point of view.

The study's strengths include a long follow-up period for what is still a relatively new technique to North America. With a minimum of 1 year follow-up we anticipated adequate capture of both short and long-term complications. The study also allowed for a robust evaluation of MIPS since objective surgical and subjective patient factors were assessed. The sample size $(N=12)$ for the semi-structured interview was adequate to achieve thematic saturation [18]. The patients will continue to be followed and watched closely to ensure ongoing stability.

\section{Conclusion}

As one of the first North American adopters of the MIPS procedure, we thought it diligent to perform a quality assurance project using our own original prospective cohort. Our findings conclude both device stability and patient satisfaction with no loss of fixtures.

Consequently, we have adopted MIPS as our procedure of choice for the placement of all percutaneous BAHDs.

\section{Abbreviations}

BAHD: Bone Anchored Hearing Devices; $\mathrm{BCHI}$ : Bone Conduction Hearing Implants; HCP: Healthcare Providers; IPS: Inflammation Pain Skin height; MIPS: Minimally Invasive Ponto Surgery; OR: Operating Room; SSQ: Surgical Satisfaction Questionnaire

\section{Acknowledgements}

The authors gratefully acknowledge the assistance of the following individuals who were instrumental in helping coordinate and evaluate MIPS patient's in follow-up parallel research clinics:

Carla Roberts (Administrative Assistant, Victoria General Hospital, Halifax). Mamoona Khalid-Raja (Otology Fellow, Dalhousie University).

\section{Funding}

None.

\section{Availability of data and materials}

Not applicable.

\section{Authors' contributions}

YS was responsible for the preparation of the manuscript, coordinating the research clinics to conduct follow-up of the MIPS cohort. YS also completed the literature review, liaised with necessary hospital departments and analyzed the data. NJ prepared and edited of the manuscript, and was the primary surgeon as Otology Fellow for some of the MIPS cases. DPM was the lead surgeon for all MIPS cases, contributed to and edited the manuscript and developed the discussion.

\section{Author's information}

YS is a third-year medical student at Dalhousie University. NJ was an Otology Fellow at Dalhousie University and is currently a consulting ENT surgeon and senior clinical lecturer at both Sydney and Macquarie Universities, Sydney, Australia. DPM is a Consultant in Adult and Paediatric Otology/Neurotology at the Queen Elizabeth II Health Science Centre in Halifax Nova Scotia and is an Associate Professor at Dalhousie University.

\section{Ethical approval and consent to participate}

Institutional permission from Nova Scotia Health Authority Research Ethics Board was obtained to conduct the quality assurance of the new MIPS technique. No formal ethics approval was required as per Article 2.5 of the TCPS and therefore no review number was generated for this project.

\section{Consent for publication}

See above.

\section{Competing interests}

DPM has participated in scientific meetings, MIPS prototype development and workshops arranged by Oticon Medical where travel and accommodation costs were provided. YS and NJ have none to declare.

\section{Publisher's Note}

Springer Nature remains neutral with regard to jurisdictional claims in published maps and institutional affiliations.

\section{Author details}

${ }^{1}$ Faculty of Medicine, Dalhousie University, Halifax, NS, Canada. ${ }^{2}$ Division of Otolaryngology - Head and Neck Surgery, Dalhousie University, Halifax, NS, Canada. ${ }^{3}$ Discipline of Surgery, Sydney Medical School, University of Sydney, Sydney, Australia. ${ }^{4}$ Department of Otolaryngology - Head and Neck Surgery, Faculty of Medicine and Health Sciences, Macquarie University, Sydney, Australia. ${ }^{5}$ QEIl Health Science Center - VG Site Otolaryngology, 5820

University Ave - Rm 3037, Halifax, NS B3H 2Y9, Canada.

Received: 10 July 2018 Accepted: 4 November 2018

Published online: 20 November 2018

\section{References}

1. Hultcrantz M. Outcome of the bone-anchored hearing aid procedure without skin thinning: a prospective clinical trial. Otol Neurotol. 2011; 32:1134-9.

2. Sardiwalla $Y$, Jufas N, Morris DP. Direct cost comparison of minimally invasive punch technique versus traditional approaches for percutaneous bone anchored hearing devices. J Otolaryngol - Head Neck Surg. 2017:46:4-9.

3. Johansson M, Holmberg M, Hultcrantz PM. Bone anchored hearing implant surgery with tissue preservation - a systematic literature review. Oticon Med Rev. 2015. https://www.oticonmedical.com/-/media/medical/main/files/ for-professionals/bahs/surgical-materials/papers/eng/literature-review--tissue-preservation---english---m52107.pdf?la=en.

4. Johansson $M L$, et al. Short-term results from seventy-six patients receiving a bone-anchored hearing implant installed with a novel minimally invasive surgery technique. Clin Otolaryngol. 2017:42:1043-8.

5. Bonilla A, Magri C, Juan E. Findings from the experience with the punch technique for auditory osseointegrated implants: a retrospective single center comparative study. Acta Otorrinolaringol Esp. 2017;68:309-16.

6. Bennett, A., Banigo, A., Lovegrove, D. \& Wood, M. Comparison of non soft tissue reduction techniques for BAHA insertion: open approach vs. MIPS in OSSEO (2017).

7. Johansson M, Holmberg M. Design and clinical evaluation of MIPS - a new perspective on tissue preservation. Oticon Med. 2014:1-12. https://doi.org/ 10.13140/RG.2.1.3624.7762.

8. Calon, T. G. A. et al. Minimally invasive Ponto surgery compared to the linear incision technique without soft tissue reduction for bone conduction hearing implants: study protocol for a randomized controlled trial. Trials 17, 540 (2016).

9. Calon ÃTGA, et al. Minimally invasive Ponto surgery versus the linear incision technique with soft tissue preservation for bone conduction hearing Implants : a multicenter randomized controlled trial. Otol. Neurotol. 2018;39:882-93.

10. Reyes RA, Tjellstrom A, Granstrom G. Evaluation of implant losses and skin reactions around extraoral bone-anchored implants: a 0-to 8-year follow-up. Otolaryngol Neck Surg. 2000;122:272-6.

11. Tjellstrom A, Granstrom G. Long-term follow-up with the bone-anchored hearing aid: a review of the first 100 patients between 1977 and 1985. Ear Nose Throat J. 1994;73:112-4. 
12. D'Eredità R, Caroncini M, Saetti R. The new baha implant: a prospective osseointegration study. Otolaryngol - Head Neck Surg (United States). 2012; 146(979-983)

13. Kruyt IJ, Nelissen RC, Johansson ML, Mylanus EAM, Hol MKS. The IPS-scale: a new soft tissue assessment scale for percutaneous and transcutaneous implants for bone conduction devices. Clin Otolaryngol. 2017:42:1410-3.

14. Holgers KM, Tjellstrom A, Bjursten LM, Erlandsson BE. Soft tissue reactions around percutaneous implants: a clinical study of soft tissue conditions around skin-penetrating titanium implants for bone-anchored hearing aids. Am J Otol. 1988;9:56-9.

15. Wazen JJ, et al. Successes and complications of the Baha system. Otol Neurotol. 2008;29:1115-9.

16. Hol MKS, et al. The bone-anchored hearing aid: quality-of-life assessment. Arch Otolaryngol Head Neck Sur. 2004;130:394-9.

17. AruArunachalan PS, Kilby D, Meikle D, Davison T, Johnson I. Bone-anchored hearing aid: quality of life assess by Glasgow benefit inventory. Clin Otolaryngol Allied Sci. 2000;25:570-6.

18. Ando, H., Cousins, R. \& Young, C. Achieving Saturation in Thematic Analysis: Development and Refinement of a Codebook. Compr. Psychol. 3, 03.CP.3.4 (2014)

Ready to submit your research? Choose BMC and benefit from:

- fast, convenient online submission

- thorough peer review by experienced researchers in your field

- rapid publication on acceptance

- support for research data, including large and complex data types

- gold Open Access which fosters wider collaboration and increased citations

- maximum visibility for your research: over $100 \mathrm{M}$ website views per year

At BMC, research is always in progress.

Learn more biomedcentral.com/submissions 